\title{
Effect of Health Promoting Lifestyle Modifications on Quality of Life among Menopausal Women
}

\author{
Eman A. Soliman El-Hosary ${ }^{1}$, Amany Ali Abd El-Salam ${ }^{2}$ \\ ${ }^{1}$ Lecturer of Maternal and Newborn Health Nursing, Faculty of Nursing, Menoufia University, \\ Egypt. And Ass.Prof in College of Applied Medical Sciences, Shqura University, KSA. \\ ${ }^{2}$ Lecturer of Maternal and Newborn Health Nursing, Faculty of Nursing, Menoufia University, \\ Egypt.
}

\begin{abstract}
Menopause-related signs and symptoms such as weight gain, night sweats, hot flashes, and reduced sexual functioning all have passive effects on "life quality", and impacts daily activities such as leisure activities, work, and sleep. The Aims of the study were to determine the effect of lifestyle modification on promoting life quality and improving health promotion behaviors among postmenopausal women. The quasi-experimental study with "preposttest" design was utilized at primary and secondary schools in Menoufiya GovernorateShebin Al-Kom- Arab Republic of Egypt. A total of 200 postmenopausal women between 45 to 60 years of teachers and employee were recruited in the study. Four tools were developed and used for data collection; 1) A structured Interviewing Questionnaire, 2) Menopause Rating Scale; 3) Utain Quality of Life Scale 4) Health Promoting Lifestyle Profile. Results showed that there were statistically significant differences between the control and intervention groups regarding promoting life quality and improving health promotion behaviors before and after the nursing intervention. The study concluded that the healthy lifestyle modifications improved scores of life quality among postmenopausal women in immediately and three months after the nursing intervention. Therefore these modifications can be used by all postmenopausal women to improve their health and fineness of life.

Keywords: Health promotion lifestyle modification- Quality of Life-Menopausal Women.
\end{abstract}

\section{INTODUCTION}

Menopause is a universal event in the midlife, it is an important life event in women, which differs from illness or diseases. It is a transition period in life eventuating around the age of fifty years in the most developed countries. (Leplege and Dennerstein, 2009) Menopause challenges cognition, symptoms, and self-identity. Menopause is defined by twelve months of amenorrhea after the cessation of the final menstruation without obvious pathological causes Soules et al (2008), Elhossiny et al (2015). It conveys absence of estrogen secretion and complete ovarian follicular depletion. Postmenopause describes the duration following the cessation of the final menstruation; early postmenopause is defined as the first 5 years after the final menstrual period. It is characterized by complete reduction of ovarian function and accelerated bone loss, and late postmenopause begins 5 years after the cessation the final menstrual period and ends with the death Bhattacharya and Jha (2010).

Menopausal symptoms affect all aspects of life quality. Mood swings, trouble sleeping, a headache, and vasomotor symptoms such as hot flashes, and night sweats, somatic symptoms such as vaginal atrophy and dryness, and dyspareunia, as well as psychological symptoms such as anxiety, difficulty in concentrating, overreacting to minor upsets, forgetfulness, and quickly being irritated Bosworth et al (2007), Vandenakker and Glass (2006). The effect, duration, and severity of these symptoms different from woman to woman like menstruation Gold et al (2005). Some women have severe signs and symptoms that extremely impact 


\section{Effect of Health Promoting Lifestyle Modifications on Quality of Life among Menopausal Women}

their social and personal functioning, and life quality Anderson et al (2004). Unfortunately the majority of these women cannot accommodate in this period of their life because they are not aware of the changes brought about by menopause Kim et al (2012).

The health promotion is the art of lifestyle modifications or change, it is a very important requirement in the human societies to promote healthy lifestyle behaviors and improve quality of life to reach the desirable perfection

\section{Golden et al (2015).}

The basic and important goals of health services for all of the people in the 22nd century are to enhance "life quality". World Health Organization defined "life quality" is the fineness of life as the person's perception of their status in life according to the value and cultural systems of the individual lives in, considering their expectations, aims, "worries" and standards World Health Organization (2005). Life quality is the basic objective of the health care and a remarkable factor for individual health and it is used to design and evaluate nursing care intervention programs in postmenopausal women, life quality refers to goodness of life and aspects pertaining to health based on a combination of symptoms without considering social, physical or emotional function Yekkefallah (2006). Hence, the term "life quality" in menopausal women often refers to the menopausal symptoms of hot flushing, vaginal dryness, and night sweats. Definitely, these signs and symptoms impact the women's life quality; other dimension of individual health, mental function, and self-satisfaction are also very important Carpenter (2001).

The present study was conducted to address the magnitude of refinement health-related life quality in postmenopausal women and estimate the impact of healthy lifestyle modifications on improving life quality among menopausal women.

Purposes of the study: the purposes of the current study is to examine the effect of the healthy lifestyle modifications among postmenopausal women on (1) Minimizing menopausal symptoms. (2) Improving health promotion behaviors. (3) Promoting quality of life.

Research hypothesis: To fulfill the aim of the current study the following research hypothesis were formulated.

H1. Menopausal women who receive health promoting lifestyle modifications will have fewer menopausal symptoms than before the nursing intervention.

H2. Menopausal women who receive health promoting lifestyle modifications will improved health behaviors.

H3. Menopausal women who receive health promoting lifestyle modifications will improved quality of life.

\section{Significant of the study:}

Women will spend one-third of their life after menopause because of increasing life expectancy and lifespan, there is many psychological and physical changes occur to menopausal women. Menopause is an important life event in women which differs from illness. It is a transition period in life. Several studies indicated that quality of life was collapsed in postmenopausal women, because postmenopausal period is related to multiple physiological and psychological changes that may impact women's health outcomes, it is estimated that about seventy-five percent of women experience acute signs and symptoms after menopause and more than $80 \%$ experience menopausal symptoms with varying degrees of severity that affect quality of life, especially many women have low information and experience 


\section{Effect of Health Promoting Lifestyle Modifications on Quality of Life among Menopausal Women}

about menopausal transition issues, reinforcement the importance of a healthy lifestyle modifications for menopausal women to increase women's awareness about menopause and improve their health behaviors and quality of life McKinney et al(2012), Ibrahim et al (2015).

\section{SUBJECTS AND METHODS}

Research Design, setting and timing: The quasi-experimental study with a pre-post-test design was used in menopausal women during the academic year 2017-2018 in Menoufiya Governorate- Shebin Al-Kom- Arab Republic of Egypt.

Sampling size and technique: Based on the previous similar studies and inclusion criteria of the study, a total of (200) women was allocated into two groups; control group $(n=100)$ and intervention group $(n=100)$. Teachers and employee of four schools had been participated in the study, two elementary schools and two secondary schools. The sample size was calculated at the confidence level of ninety-nine percent and an acceptable margin of error at ten percent, the sample size was calculated using the following equation Ambe et al (2010).

$$
\mathrm{n}=
$$

- $\mathrm{n}=$ sample size

- $\mathrm{z}=\mathrm{z}$ value for $99 \% .=2.57$

- $\mathrm{p}($ prevalence $)=0.5$

- $\mathrm{q}=(1-\mathrm{p})=(1-0,50)$

- $\mathrm{e}=$ margin of error $=0.10$

$\mathrm{n}=(2.57)^{2} \times 0.50 \times(1-0.50) \div(0.10)^{2}=$ 189

The researcher added 11 cases to the total sample size to become 200 and the researcher divided it into 100 interventions and 100 control group.

Inclusion criteria were the following: 1. Postmenopausal women (twelve or more months of amenorrhea); 2. Not using any kinds of medication or hormonal replacement therapy sex months prior to the study (herbal/chemical); 3. Not doing any physical exercises more than five minutes per day and twenty minutes per week. 4. Agreement to tourney in the research.

Exclusion criteria were the following: 1. Women with physical, mental, or chronic illness. 2. Women with uncontrolled medical conditions such as hypertension, diabetes, heart disease, musculoskeletal conditions, who were undergoing treatment for cancer, or were in remission. 3. Hysterectomized women.

Scores for "quality-of-life" in the intervention and control groups were evaluated and compared in two stages (before educational intervention, immediately after the intervention, and three months after the nursing intervention) both between and within the groups as changes pre and post nursing intervention about healthy lifestyle modifications.

\section{Tools for data collection:}

Four types of tools were used for data collection. These consisted of women's" structured interviewing questionnaire, menopause rating scale, Utain quality of life scale, and HealthPromotion Lifestyle Profile.

- Part one: A Structure Interviewing Questionnaire: Was developed by the researchers after extensive literature review related to 1-a) Demographic characteristics (age, name \& educational level); \& 1-b) Medical and obstetrical data.

* Part two: Menopause Rating Scale: It is developed by Heinemann et al (2003) and translated by the researchers. This scale used for assessing the severity of menopausal signs and symptoms in the study. This is a selfadministered instrument which has 


\section{Effect of Health Promoting Lifestyle Modifications on Quality of Life among Menopausal Women}

been widely validated and used in many epidemiological and clinical studies. It consisted of three domains; physical, psychological, and urogenital symptoms. These items are scored based on a fourpoint Likert scale with four possible responses: 1(mild), 2(moderate), 3 (severe), and 4 (very severe).

* Part three: Health Promotion Lifestyle Profile: The original was developed by Walker in (1987) and translated by the researchers. This profile based on Pender's health promotion model and it is suitable for using in the study Pender et al (2011). This profile contains fiftytwo items and six subscales to measure the frequency of the healthpromoting behaviors. It is measured in six domains; health responsibility, physical activity, nutrition, spiritual growth, interpersonal relations, and stress management. These items are scored based on a four-point Likert scale with four possible responses: 1(never), 2(sometimes), 3 (often), and 4 (routinely). The total score is obtained by calculating the mean of the responses to that subscale's items. Overall score range from 52 to 208. According to Walker et al (1996), Cronbach's alpha was 0.96 and 0.79-0.87 for the subscales.

* Part four: Utain Quality of Life Scale: Is a modification of the original Utain questionnaire from the 1970 s. It was developed by Utain (2002) from the old questionnaire and translated by the researchers; it designed to assess the sense of well-being and severity of quality of life burden among menopausal women. This scale contains twenty-three items. It is measured in four domains; occupational quality of life, health, psychosocial quality of life, and sexual quality of life. These domains are scored based on a five-point
Likert scale with five possible responses: 1(not true), 2(slightly true), 3 (moderately true), 4 (true), and 5 (very true). The total score is obtained by computing the four domains. The total score of the Utain quality of life is ranged from 48 to 100 Utain (2002).

\section{Content validity and reliability}

Study tools were submitted to a panel of five experts in the field of maternity nursing, to test the content validity. Modifications were done according to the panel's judgment on the clarity of sentences and content appropriateness. Reliability analysis was conducted to investigate the instrument internal consistency which used in the study. Internal consistency describes the extent to which all the questionnaire items measure the same concept or construct. Cronbach alpha coefficients were calculated to examine the measurement reliability with multipoint items. The accepted values of Cronbach's alpha coefficient range from 0.60 to 0.95 . The questionnaire items of the present study were proven reliable where $\alpha=0.91$ Sun et al (2007), Tavakol and Dennick (2011).

\section{Pilot Study}

It was conducted on $10 \%$ of the study sample, were selected randomly and excluded from the main research sample. Its aim was to evaluate the clarity and simplicity of the tools. It also helped in the determination of the time needed to fill in the forms of the questionnaire. According to the results of this study, simple modifications were done as canceling and rephrasing some questions.

\section{Ethical consideration}

An official permission letters was granted from the Dean of the Faculty of Nursing at EL- Menoufia University and Vice Dean for post graduates studies and researches to the directors of the schools. The researchers ensured that the study posed no risks or hazards 


\section{Effect of Health Promoting Lifestyle Modifications on Quality of Life among Menopausal Women}

to their health and their participation in the study were voluntary. Therefore, nature of the study, the objectives, its importance safety and confidentiality were explained. Menopausal women who were willing to participate in the study and met the inclusion criteria were approached by the researchers and asked for verbal and written consent to confirm their acceptance, and all events that occurred during data collection were considered confidential.

\section{Fieldwork:}

After determination of training and educational needs of women, nursing intervention was performed weekly, for five consecutive weeks; each session lasted forty five to sixty minutes. Sittings in the form of fifteen-person discussion groups. "The first session" included knowledge about female genital organs, the physiological changes of menopause. "The second session" describing the symptoms and complications of menopause and how to deal with menopausal symptoms. "The third session" about proper nutrition, exercises, and the importance of performing breast self-examination, Pap smear, and mammogram. "The fourth session" about the importance of follow up and visiting the physician and calcium and vitamin D supplements described by the physician. "The fifth session" include stress-management and education to their husbands and the best of the friend about menopausal symptoms and action plan for health care in menopause. Different educational methods were used including interactive lecture and group discussion, and media such as the pictures, the poster, slide-show, and flip chart. At the end of each session, the outline of the information was delivered to the women and at the end of the whole period of nursing intervention, brochures and booklets containing all of the presented information accompanied with the CD containing PowerPoint presentations and videos about the relaxation techniques and strategies was given to the women in "the intervention group". The control group received no education and they had no contact with the intervention group.

The study data were collected using the four tools; the interviewing questionnaire, menopausal rating scale, health promotion lifestyle profile, and Utain quality of life scale for the two groups.

At the end of the third month post the nursing intervention, women of all groups completed the Utain Quality of Life Scale and Health Promotion Lifestyle Profile.

\section{Statistical design:}

Data were processed using SPSS version 20 for windows. We used paired $t$-test in order to compare the mean scores for diverse criteria (total score for quality-of-life) - within groups pre and post the nursing intervention. Independent $t$-test was used in order to compare the mean scores between groups before and after the nursing intervention. - Chi-square test was used for determining the differences among demographic status between groups and the quality-of-life measures in relation to age, the mean age at menopause and level of education. Statistical significance was considered at $\mathbf{p}$-value $\mathbf{< 0 . 0 5}$.

\section{RESULTS}

Table (1) showed that there were no statistically significant differences between the two groups regarding basic demographic characteristics of the "menopausal women.

Table (2) presented that there were highly statistically significant differences between the two groups in the mean score of the menopausal rating scale pre and post intervention.

Table (3) presented that there were highly statistically significant 


\section{Effect of Health Promoting Lifestyle Modifications on Quality of Life among Menopausal Women}

differences between the two groups in the mean score of the "healthpromoting lifestyle profile" before and after the intervention.

Table (4) showed that there were highly statistically significant differences between the two groups in the Utain quality of life scores before, instantly and three months post nursing intervention.
Figure (1) clarified that there was a significant improvement among intervention group women regarding all dimension of Utain quality of life scale in the pre-intervention, immediately post-intervention, and three months post-intervention.

Table (1): Basic Demographic characteristics of the Menopausal Women (N=200)

\begin{tabular}{|c|c|c|c|c|c|}
\hline \multirow{3}{*}{$\begin{array}{l}\text { characteristics } \\
\text { Age(years) } \\
\leq 54 \text { years } \\
\geq 55 \text { years }\end{array}$} & \multicolumn{2}{|c|}{$\begin{array}{c}\text { Intervention Group } \\
(\mathrm{n}=100)\end{array}$} & \multicolumn{2}{|c|}{$\begin{array}{c}\text { Control Group } \\
(n=100)\end{array}$} & \multirow{3}{*}{$\begin{array}{r}\text { P-value } \\
0.198\end{array}$} \\
\hline & No & $\%$ & No & $\%$ & \\
\hline & $\begin{array}{l}\mathbf{5 0} \\
\mathbf{5 0}\end{array}$ & $\begin{array}{l}\mathbf{5 0} \\
\mathbf{5 0}\end{array}$ & $\begin{array}{l}60 \\
40\end{array}$ & $\begin{array}{l}60 \\
40\end{array}$ & \\
\hline $\begin{array}{l}\text { Age at menopause } \\
<50 \text { years } \\
\geq 50 \text { years }\end{array}$ & $\begin{array}{l}70 \\
\mathbf{3 0}\end{array}$ & $\begin{array}{l}70 \\
\mathbf{3 0}\end{array}$ & $\begin{array}{l}66 \\
34\end{array}$ & $\begin{array}{l}66 \\
34\end{array}$ & 0.542 \\
\hline $\begin{array}{l}\text { Parity } \\
\leq 3 \\
4-6 \\
>6 \\
\end{array}$ & $\begin{array}{c}5 \\
53 \\
42 \\
\end{array}$ & $\begin{array}{c}5 \\
53 \\
42\end{array}$ & $\begin{array}{c}3 \\
48 \\
49 \\
\end{array}$ & $\begin{array}{c}3 \\
48 \\
49\end{array}$ & 0.436 \\
\hline $\begin{array}{l}\text { Marital status } \\
\text { Married } \\
\text { Single } \\
\text { Widowed } \\
\end{array}$ & $\begin{array}{c}89 \\
2 \\
9\end{array}$ & $\begin{array}{c}89 \\
2 \\
9\end{array}$ & $\begin{array}{c}94 \\
1 \\
5\end{array}$ & $\begin{array}{c}94 \\
1 \\
5\end{array}$ & 0.215 \\
\hline $\begin{array}{l}\text { Educational level } \\
\text { Middle school } \\
\text { High school }\end{array}$ & $\begin{array}{l}75 \\
25 \\
\end{array}$ & $\begin{array}{l}75 \\
25 \\
\end{array}$ & $\begin{array}{l}85 \\
15\end{array}$ & $\begin{array}{l}85 \\
15\end{array}$ & 0.952 \\
\hline $\begin{array}{l}\text { Husband's education } \\
\text { Middle school } \\
\text { High school }\end{array}$ & $\begin{array}{l}85 \\
15\end{array}$ & $\begin{array}{l}85 \\
15 \\
\end{array}$ & $\begin{array}{l}65 \\
35 \\
\end{array}$ & $\begin{array}{l}\mathbf{6 5} \\
35 \\
\end{array}$ & 0.861 \\
\hline $\begin{array}{l}\text { Women's occupation } \\
\text { Teachers } \\
\text { Employee }\end{array}$ & $\begin{array}{l}25 \\
75\end{array}$ & $\begin{array}{l}25 \\
75\end{array}$ & $\begin{array}{l}15 \\
85 \\
\end{array}$ & $\begin{array}{l}15 \\
85\end{array}$ & 0.122 \\
\hline $\begin{array}{l}\text { Husband's Occupation } \\
\text { Employee } \\
\text { private work }\end{array}$ & $\begin{array}{l}61 \\
39 \\
\end{array}$ & $\begin{array}{l}61 \\
39 \\
\end{array}$ & $\begin{array}{l}80 \\
20\end{array}$ & $\begin{array}{l}80 \\
20\end{array}$ & 0.284 \\
\hline
\end{tabular}

Table (2): Comparison of the mean score of the Menopausal Rating Scale before and after the intervention

\begin{tabular}{|c|c|c|c|c|c|}
\hline \multirow[t]{2}{*}{ Dimension } & \multicolumn{2}{|c|}{$\begin{array}{c}\text { Intervention Group }(\mathrm{n}=100) \\
\text { Mean } \pm \text { SD }\end{array}$} & \multicolumn{2}{|c|}{$\begin{array}{c}\text { Control Group }(n=100) \\
\text { Mean } \pm \text { SD }\end{array}$} & \multirow[b]{2}{*}{ P-value } \\
\hline & $\begin{array}{c}\text { Before } \\
\text { intervention }\end{array}$ & $\begin{array}{c}\text { After } \\
\text { intervention }\end{array}$ & $\begin{array}{c}\text { Before } \\
\text { intervention }\end{array}$ & $\begin{array}{c}\text { After } \\
\text { intervention }\end{array}$ & \\
\hline Physical symptoms & $10.01(3.47)$ & $9.66(3.34)$ & $10.65(3.20)$ & $10.72(3.03)$ & $<0.001 *$ \\
\hline $\begin{array}{l}\text { Psychological } \\
\text { symptoms }\end{array}$ & 10.11(4.45) & 9.61(4.32) & $10.63(3.98)$ & $10.70(3.34)$ & $<0.001 *$ \\
\hline $\begin{array}{l}\text { Urogenital } \\
\text { symptoms }\end{array}$ & 5.91(3.67) & 4.85(2.93) & $5.26(3.63)$ & $5.68(2.99)$ & $<0.001 *$ \\
\hline Total score of MRS & $26.03(9.89)$ & $24.12(8.97)$ & $26.54(8.20)$ & $27.10(7.22)$ & $<0.001 *$ \\
\hline
\end{tabular}

* Highly statistically significant at p<0.001 


\section{Effect of Health Promoting Lifestyle Modifications on Quality of Life among Menopausal Women}

Table (3): Comparison of the mean score of the Health Promoting Lifestyle Profile

before and after the intervention $(\mathrm{N}=200)$

\begin{tabular}{|c|c|c|c|c|c|}
\hline \multirow[t]{2}{*}{ Dimension } & \multicolumn{2}{|c|}{$\begin{array}{c}\text { Intervention Group }(\mathbf{n}=\mathbf{1 0 0}) \\
\text { Mean } \pm \text { SD }\end{array}$} & \multicolumn{2}{|c|}{$\begin{array}{c}\text { Control Group }(n=100) \\
\text { Mean } \pm \text { SD }\end{array}$} & \multirow[b]{2}{*}{ P-value } \\
\hline & $\begin{array}{c}\text { Before } \\
\text { intervention }\end{array}$ & $\begin{array}{c}\text { After } \\
\text { intervention }\end{array}$ & $\begin{array}{c}\text { Before } \\
\text { intervention }\end{array}$ & $\begin{array}{c}\text { After } \\
\text { intervention }\end{array}$ & \\
\hline Spiritual growth & $24.95(4.79)$ & $26.13(4.39)$ & $24.33(5.60)$ & $24.38(5.36)$ & $<0.001 *$ \\
\hline Responsibility health & $30.44(5.00)$ & 31.74(4.96) & 30.12(5.39) & 30.18(5.38) & $<0.001 *$ \\
\hline $\begin{array}{l}\text { Interpersonal } \\
\text { relationships }\end{array}$ & $17.02(3.50)$ & 18.49(3.08) & 17.58(4.99) & 17.29(5.07) & $<0.001 *$ \\
\hline Stress management & $11.36(2.88)$ & $11.72(2.83)$ & $10.99(2.95)$ & $10.91(2.77)$ & $<0.001 *$ \\
\hline Nutrition & 18.12(3.05) & 19.11(2.77) & 18.34(3.00) & $18.24(2.98)$ & $<0.001 *$ \\
\hline Total score of lifestyle & $110.22(14.05)$ & 116.67(12.80) & $110.30(8.99)$ & 109.87(18.96) & $<0.001 *$ \\
\hline
\end{tabular}

* Highly statistically significant at $\mathbf{p}<0.001$

Table (4): Menopausal Utain Quality of Life Scores in the intervention and control groups

\begin{tabular}{|c|c|c|c|c|}
\hline Dimension & Variables & $\begin{array}{c}\text { Intervention Group } \\
(\mathrm{n}=\mathbf{1 0 0})\end{array}$ & $\begin{array}{c}\text { Control Group } \\
(\mathbf{n}=\mathbf{1 0 0})\end{array}$ & P-value \\
\hline \multirow[t]{3}{*}{ Occupational } & Before intervention & $13.64 \pm 2.82$ & $13.22 \pm 2.62$ & 0.158 \\
\hline & $\begin{array}{c}\text { Immediately after } \\
\text { intervention }\end{array}$ & $25.55 \pm 2.32$ & $13.41 \pm 2.69$ & $<0.001 *$ \\
\hline & $\begin{array}{c}\text { Three months after } \\
\text { intervention }\end{array}$ & $35.53 \pm 2.48$ & $13.52 \pm 4.42$ & $<0.001 *$ \\
\hline \multirow[t]{3}{*}{ psychosocial } & Before intervention & $12.84 \pm 2.93$ & $11.47 \pm 2.32$ & 0.839 \\
\hline & $\begin{array}{c}\text { Immediately after } \\
\text { intervention }\end{array}$ & $20.40 \pm 2.95$ & $11.20 \pm 2.51$ & $<0.001 *$ \\
\hline & $\begin{array}{c}\text { Three months after } \\
\text { intervention }\end{array}$ & $24.80 \pm 2.29$ & $11.20 \pm 2.10$ & $<0.001 *$ \\
\hline \multirow[t]{3}{*}{ Sexual } & Before intervention & $4.55 \pm 3.37$ & $4.06 \pm 2.53$ & 0.556 \\
\hline & $\begin{array}{c}\text { Immediately after } \\
\text { intervention }\end{array}$ & $8.73 \pm 3.36$ & $3.52 \pm 2.23$ & $<0.001 *$ \\
\hline & $\begin{array}{c}\text { Three months after } \\
\text { intervention }\end{array}$ & $12.77 \pm 3.24$ & $2.25 \pm 1.29$ & $<0.001 *$ \\
\hline \multirow[t]{3}{*}{ Health } & Before intervention & $16.53 \pm 2.89$ & $11.31 \pm 2.70$ & 0.664 \\
\hline & $\begin{array}{c}\text { Immediately after } \\
\text { intervention }\end{array}$ & $21.13 \pm 2.65$ & $11.10 \pm 2.58$ & $<0.001 *$ \\
\hline & $\begin{array}{c}\text { Three months after } \\
\text { intervention }\end{array}$ & $26.82 \pm 2.77$ & $11.27 \pm 2.10$ & $<0.001 *$ \\
\hline
\end{tabular}

The data are presented as mean \pm standard deviation $*$ Highly statistically significant at $\mathrm{p}<$ 0.001

\section{The Mean Score of Utain Quality of Life Scale in the Intervention Group}

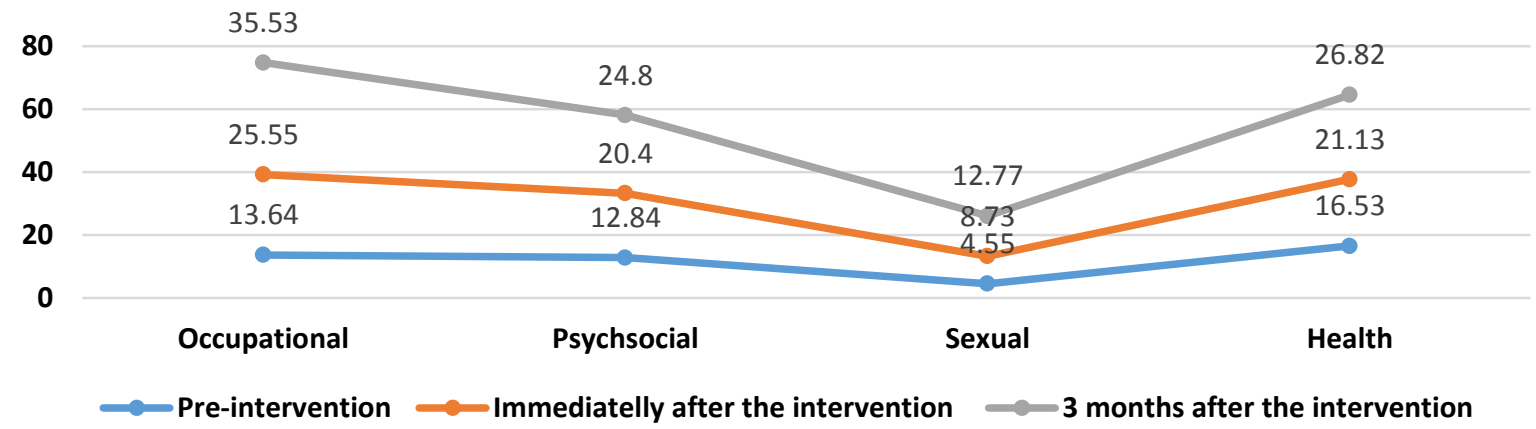

Figure (1) the mean score of Utain quality of life scale in the intervention group 


\section{DISCUSSION}

An objective of this research is to evaluate the influence of lifestyle modification in promoting healthy behaviors and improving quality of life among menopausal women. Menopause rating scale, healthpromoting lifestyle profile, and Utain quality of life scale has been used to test the effect of lifestyle modifications on promoting healthy lifestyle behaviors and improving fineness of life among postmenopausal women.

The result of this paper showed that the "lifestyle modifications" improved scores of Quality of Life among menopausal women in instantly and three months after the nursing management for all dimensions of life quality, this result of the study congruent with Norozi et al (2011) which conducted a same research in Iran and in the study three months post lifestyle modifications in the case group, scores of occupational ,psychological, mental, vasomotor, physiological, and sexual domains in postmenopausal women were recovered $(\mathrm{P}<0.001)$. This result was also congruent with Moilanen et al. (2012), they concluded that the total score of Quality of Life was improved after

holding life skill training program and there was a strong relationship between unhealthy lifestyle and the severity of menopausal symptoms, but no significant differences were observed in terms of psychological and social dimension.

On the same line Chedraui et al. (2008) had made a research of a sex week's training sessions in postmenopause and the findings concluded that the "lifestyle modification" was amended quality of life among women.

The study showed that improved psychosocial dimension of quality of life among menopausal women, this result of the study "congruent with" Golyan (2005) which reported that the nursing lifestyle modification in sex sessions changed the cognitive actions of climacteric women which resulted in improving Quality of Life and autonomic nervous system activity, and also Williams et al. (2009) showed that nursing education for seven two-hour sessions in the clinic at forty five-days intervals in postmenopausal women decreased depression mode among them.

Our results showed a significant refinement in the health and psychosocial wellbeing in the "intervention group", while the "control group" had intensive regression. Therefore, the nursing management led to the enhancement of psychosocial status in the menopausal women. This finding is congruent with the research of Elavsky et al, which noted an amelioration following physical exercises among postmenopausal women. The intervention group registered a significant physical health status improvement three months after the intervention. The research of Rotem et al also reported improvement in psychological, social, and health status following nursing management in postmenopausal women.

The intervention group showed a significant betterment in "sexual dimension", which their changes were significantly better than that of the "control group. Lobo et al pointed out that the sexual aspect of a menopausal woman's life could be recovered indirectly following the improvement of hot flashes.

Furthermore, using the similar training nursing intervention program, Osinowo reported that after giving information to the postmenopausal women, an improvement of sexual activity was noted.

Our study showed that quality-of-life advanced significantly in the intervention group following nursing management while the control group showed intensive deterioration. This finding confirms that of Keefer et al. who reported an improvement in the quality-of-life following nursing education on menopausal symptoms and coping strategies.

Nursing management helped the women to cope with their menopausal signs and 
symptoms, therefor quality of life ameliorated among them. Healthy lifestyle modifications are very important for the life during the menopausal period. Finding a coping strategy to improve quality of life among postmenopausal women is very necessary.

The present study concluded that there were highly statistically significant differences between intervention and control groups in the health-promoting lifestyle profile and menopausal symptoms. This result of the study was comparable to the study of Garcia (2011) on postmenopausal women. They reported that the intervention of a healthy lifestyle education led to diminishing the postmenopausal symptoms, the results were also consistent with the study of Sehatiesshafaire et al (2014) in Iran which conducted that implanting educational healthy lifestyle modifications were effective in improving menopausal symptoms and increasing health-promoting behaviors.

On the same line, Anderson et al (2015), conducted a research on Australian postmenopausal women through the intervention of a twelve-week educational program on healthy lifestyle modification and he found it was effective in improving postmenopausal symptoms and increasing health-promoting behaviors among women. The study of Imayama et al (2011) also showed the favorable impacts of healthy lifestyle modifications, such as good nutrition and exercises, on minimizing postmenopausal psychological signs and symptoms such as anxiety, stress, and depression. Also In the research of Mansikkamakia et al (2015) on postmenopausal women, "practicing exercises reported being related to improvement and reduction of postmenopausal signs and symptoms, such as memory dysfunctions, physiological symptoms, and depressed mood. James (2012) and Patel et al (2014) also demonstrated a similar research and suggested that structured training programs about postmenopausal symptoms and their management had an affirmative impress on enhancement women's awareness and power towards the menopausal period. On the same line A äil et al (2010) concluded that the positive effects of "aerobic exercises" on decreasing menopausal symptoms and improving the healthpromoting behaviors among the menopausal women.

Our results were also congruent with the study by Rizvi et al (2012) in Pakistan which conducted high prevalence incidence of the "poor lifestyle" and chronic illness in the middle-aged women. In that study, thirty-one percent of these women had poor nutritional habits and exercises and thirtysix percent reported illness, such as hypertension, diabetes mellitus, cardiovascular illness, and arthritis.

The findings of all the researchers on the postmenopausal women had confirmed and stressed on the postmenopausal women's education and training needs in their period of life. Many of these findings had indicated the effectiveness of the educational strategy in promoting health behaviors in the management of menopausal signs and symptoms. Hence, healthy lifestyle modifications are very important to promote health and improve quality of life among the postmenopausal women.

\section{CONCLUSION AND RECOMMENDATIONS}

The findings of this study concluded that the "lifestyle modifications" in 5 nursing sessions intervention amended scores of "Quality of life" among the menopausal women in instantly and three months after the nursing management. Healthy lifestyle modifications were effective in improving quality of life and health-promoting behaviors and reduced menopausal symptoms. These modifications can be used as an appropriate strategy to minimize the menopausal symptoms and improve health and quality of life. Women need to be consulted and trained continuously about control of menopausal signs and symptoms, 
healthy nutrition, and regular exercises. Hence, we recommend that a unit or part in the hospitals, health and treatment centers be conducted for training the menopausal women about healthy lifestyle and how to manage changing symptoms.

\section{REFERENCES}

Ăğl, A., Abıke, F., Daşkapan, A. (2010): Short-Term Exercise Approaches on Menopausal Symptoms, Psychological Health, and Quality of Life in Postmenopausal Women, Obstetrics and Gynecology International Journal, Ankara, 0Turkey, -6(3), 341-351.-

Ambe, J., Bello, M., Yahaya, S. \& Omotora, B. (2010). Calculating sample size, OJournal of Tropical Medicine -9 (6): 87 - 92.-

Anderson E, Hamburger S, Liu JH, Rebar RW (2004): Characteristics of Menopausal Women Seeking Assistance. $0 A m \quad J$ Obstetric Gynecology; -156:428-33.-

Anderson, D., McGuire, A., D., Porter-Steete, J., Seib, C., (2015): Decreasing the Menopausal Symptoms in Woman Undertaking A- Web-Based Multi-Model Lifestyle Intervention: - The Woman's Wellness Program. 0 Mduriatas, -81, 69-75.-

Bhattacharya.SM, Jha.AA (2010): A comparison of Health-Related Quality of Life after Natural and Surgical Menopause. OMaturitas; 86(4): 431-4.-

Bosworth HB, Bastian LA, Kuchibhatla MN, Steffens DC, McBride CM, Skinner CS, Rimer BK, Siegler IC(2007): Depressive Symptoms, Menopausal Status, and Climacteric Symptoms in Women at Midlife. OPsychosom Med; 63:603-8.-

Carpenter JS. (2001): The Hot Flash Related Daily Interference Scale:
A tool for Assessing the Impact of Hot Flashes on Quality of Life Following Breast Cancer.O J Pain Symptom Manage. ; -22:979-89.-

Chedraui P, Blumel JE, Belzares E, Bencosme A, Calle A, and Baron G, (2008): Impaired Quality of Life among Middle-Aged Women: A multicenter Latin American Study. OMaturitas. -61:323-9.-

Elavsky S, McAuley E. (2007): Physical Activity and Mental Health Outcomes during Menopause: A randomized Controlled Trial.o Ann Behav Med.; -33:132-42.-

Elhossiny Elkazeh, E.A, El-Zeftway, A.M (2015): Knowledge of Women Reproductive Age about Menopausal Problems \& Preventive Health Behaviors in Tanta City, Al-Gharbyia Governorate, Egypt. OJournal of Nursing and Health Science, -4(3), 51-63.-

Garcia, C.L., Gomez-Calcerrada, S.G. (2011): Cognitive-Behavioral Intervention among Women with Slight Menopausal Symptoms: A Pilot Study. OThe Spanish Journal of Psychology, -14(1), 344-355.-

Gold EB, Sternfeld B, Kelsey JL, Brown C, Mouton C, Reame N, Salamone L, Stellato R. (2005): Relation of Demographic and Lifestyle Factors to Symptoms in a Multi-Racial/Ethnic Population of Women 40-55 years of age. OAm J Epidemiol; -152:463-73.-

Golden, S.D, Mcleory, k.R, Green, L.W (2015): Upending the Social Ecological Model to Guide Health Promotion Efforts toward Policy and Environmental Changes. OHealth Education Behavior; 24(1); 8-14.-

Golyan Tehrani Sh, Mir Mohammad Ali M, Mahmoudi M, Khaledian Z. (2005): Study of quality of life and its patterns in different stage of 
menopause for women in Tehran. OJ Hayat. ; -8:33-41.-

Heinemann LAJ, Potthoff $P$, and Schneider HP. (2003): The International version of the Menopause Rating Scale (MRS), OHealth Qual Life Outcomes. -p. 28.-

Ibrahim, Z. M.,Ahmed, W.A., ElHamid, S.A. (2015): Prevalence of Menopausal Related Symptoms $\&$ their Impact on Quality of Life among Egyptian Women. OClinical \& Experimental Obstetrics \&Gynecology, -2(1), 161-167.-

Imayama, I., Alfano, C.M, Kong, A., Faster-Schubert, K.E (2011): Dietary Weight Loss and Exercises Interventions Effects on Quality of Life in Overweight/Obese Postmenopausal Women. A Randomized Control Trial. Interventional Journal of Behavioral Nutrition \& Physical Activity, 8(118), -2-12.-

James, J. (2012): A Study to Evaluate the Effectiveness of Structured teaching Programme on Knowledge Regarding Menopausal Problems \& its Premedical Measures among Middle Age Women in Selected Rural Areas. Bangalore. ORajive Gandhi University of Health Sciences. Bakgolar Karnataka, - 1-94.-

Keefer L, Blanchard EB. (2005): A Behavioral Group Treatment Program for Menopausal Hot Flashes: Results of a Pilot Study.0 Apple Psychophysiology Biofeedback. ; -30:21-30.-

Kim, I.K, Choi, H.M, Kim, M.H (2012): Menopausal Knowledge \&Management in Peri-menopausal Women. OThe Korean Society of Menopause, -18, 124-131.-

Leplege A, Dennerstein L. (2009): Menopause and Quality of Life.
Quality of Life Research; 9:68992.-

Lobo A. (1999): Treatment of the Postmenopausal Women: Basical and Clinical Aspects. Philadelphia: -Lippincott Williams and Wilkins.-

Mansikkamakia, B.K., Ritanena, J., Malilad, N., (2015): Physical Activity \& Menopause-Related Quality of Life. A PopulationBased Cross-Sectional Study. OMaturitas, -80, 69-74.-

McKinney ES, Ashwill JW, Murry SS, (2012): Maternal Child Nursing. ST Louise: OElsevier Science Health Science Division.-

Moilanen JM, Aalto AM, Raitanen J, Hemminki E, Aro AR, Luoto R. (2012): Physical Activity and Change in Quality of Life during Menopause--an 8-Year Follow-up Study. OHealth Qual Life Outcomes. ; 10:8. doi: 10.1186/1477-7525-10-8.-

Norozi E, Mostafavi F, Hassanzadeh A, Moodi M, Sharifirad G. (2011): Factors Related with Quality of Life among Postmenopausal Women in Isfahan, Iran, based on Behavioral Analysis Phase of PRECEDE Model.OHealth System Res.; 7(3):267-77.-

Osinowo HO. (2003): Psychosocial Factors Associated with Perceived Psychological Health, Perception of Menopause and Sexual Satisfaction in Menopausal Women and Controls. OWest Afr J Med.; -22:225-31.-

Patel, V., Koshy, S., Ravindra, H.N., (2014): Effectiveness of Structured Teaching Programme on Knowledge Regarding Menopausal Symptoms \& its Management among Women. OJournal of Nursing \& Health Science, -3(3), 22-26.-

Pender, N., Murdaugh,J.,Parsons, M.(2011): The Health Promotion 
Model Manual. OHealth Promotion in Nursing Practice, - 1-17.-

Rizvi, S.A., Jalil, F., Azam, S. (2012): Prevalence of Menopause, Chronic illnesses \& lifestyle of MiddleAged Women in Karachi, Pakistan, ONational Library of Medicine Enlisted Journal, -5(4), 347-354.-

Rotem M, Kushnir T, Levine R, Ehrenfeld M. (2005): A psychoeducational Program for Improving Women's Attitudes and Coping with Menopause Symptoms. Obstetric Gynecology Neonatal Nurs. ; -34:233-40.-

Sehatiesshafaire, F., Mirghafourvand, M., Tafari, M. (2014): Effect of Education through Support Group on Early Symptoms of Menopause: A Randomized Controlled Trial. 0Journal of Caring Science, -3(4), 247-256.-

Soules MR, Sherman S, Parrott E, Rebar R, Santoro N, Utian W, Woods N.( 2008): Executive Summary: Stages of Reproductive Aging Workshop (STRAW). 0Fertil Steril; -76:874-8.-

Sun.W, Chou. C. P, Stacy.A, Unger.J, \& Gallaher. P (2007): SAS and SPSS Macros to Calculate Standardized Cronbach's Alpha Using the Upper Bound of the Phi Coefficient for Dichotomous Items. OBehavior research methods, -39(1), 71-81.-
Tavakol.M, and Dennick. R (2011): Making Sense of Cronbach's alpha. OInternational Journal of Medical Education, -2, 53.-

Utain WH (2002): The Utain Quality of Life Scale: Development and Validation of an Instrument to Quantify Quality of Life through and beyond Menopause; -9:402410.-

Vandenakker CB, Glass DD (2006): Menopause and Aging with Disability. OPhys Med RehabilClin N Am; -12:133-51.-

Walker, S.N., Hill-polerecky (1996): Psychometric Evaluation of the Health-Promoting Life-Style Profile. ONursing Research, -36(2), 76-80.-

Williams RE, Levine KB, Kaliliani L, Lewis J, Clark RV. (2009): Menopause-specific Questionnaire Assessment in US Populationbased Study Shows Negative Impact on Health-related Quality of Life. OMaturitas. -62:153-9.-

World Health Organization (2005): Quality of Life Assessment: International Perspectives. OBerlin: Springer.-

Yekkefallah L. (2006): The Effect of Physical Exercise on the Pulmonary Function and Quality of Life in Asthmatic Patients. OJ Sabzevar School of Med Sci; 12:14-9.- 